\section{South African Eye Study (SAES): ethnic differences in central corneal thickness and intraocular pressure}

SO Baboolal and DP Smit

\begin{abstract}
Purpose Glaucoma is the leading cause of irreversible blindness worldwide. South Africa has a diverse population but there is a lack of published ethnic specific normative data. The purpose of the study is to determine the distribution of intraocular pressure (IOP) and central corneal thickness (CCT) values in a multi-ethnic South African population and to determine additional systemic and ocular factors that influence IOP and CCT.

Patients and methods This cross-sectional study included a total of 402 participants with 706 eyes aged 18-94 years. Participants underwent a standardized intervieweradministered questionnaire for risk factor assessment followed by a full ophthalmic examination. The averages of six IOP readings were measured with an Icare PRO tonometer and CCT was measured with a Pentacam.

Results The mean CCT readings in the African, Mixed ethnicity, and Caucasian participants were $514.77 \pm 31.86,531.77 \pm 35.17$ and $549.97 \pm 30.51 \mu \mathrm{m}(P<0.001)$. The mean IOP in the African, Mixed ethnicity, and Caucasian participants were $15.51 \pm 2.49$, $15.09 \pm 2.12$, and $15.13 \pm 2.53 \mathrm{~mm} \mathrm{Hg}(P=0.07)$. Africans had significantly higher IOP than Mixed ethnicity $(P=0.034)$ and Caucasians $(P=0.011)$. Hypertensives had a higher IOP $(P=0.03)$. Age and pseudophakia were associated with a lower IOP $(P<0.001)$ and higher CCT $(P<\mathbf{0 . 0 0 1})$. There was a strongly positive correlation between CCT and IOP $(\beta=0.021 ; P<0.001)$.

Conclusions In the South African Eye Study (SAES), Africans had the thinnest corneas and highest IOP followed by Mixed ethnicity and Caucasians. Including systemic and ocular factors that influence IOP specific to each population and ethnic group, will lead to
\end{abstract}

a more accurate clinical risk stratification in glaucoma management.

Eye (2018) 32, 749-756; doi:10.1038/eye.2017.291; published online 12 January 2018

\section{Introduction}

Glaucoma is the leading cause of irreversible blindness globally. The highest prevalence of open-angle glaucoma occurs in blacks of African descent. Internationally, there are an estimated 60 million people with glaucomatous optic neuropathy and an estimated 8.4 million people who are blind as a result of glaucoma. These numbers are set to increase to 80 million and 11.2 million, respectively, by $2020 .^{1}$ In Africa, glaucoma accounts for $15 \%$ of blindness and it is the region with the highest incidence and prevalence of blindness relative to other regions worldwide. $^{2}$

By the year 2020, it is predicted that the number of people with open-angle glaucoma and angle closure glaucoma in Africa will be 8359451 and Africa will have the highest ratio (4.39\%) of glaucoma to adult population. ${ }^{3}$ There is some evidence that glaucoma has an earlier age of onset in blacks ${ }^{4,5}$ and has a more aggressive clinical course. ${ }^{6-8}$ In Africa, there are the additional factors of poor awareness, ${ }^{9-16}$ poor access to care, and less than optimal diagnosis and management. ${ }^{17-24}$ Socio-economic deprivation exacerbates the situation, leading to very late presentation. ${ }^{25-30}$ Thus, in Africa, glaucoma has been referred to as the 'silent thief of sight. ${ }^{\text {'1 }}$

Central corneal thickness (CCT) affects intraocular pressure measurements as a thicker cornea will cause a higher-than-actual reading to be obtained and vice versa with a thinner cornea. ${ }^{32,33}$ There are various formulas and tables (Ehlers, Dresden, Doughty, Kohlhaas) to adjust intraocular pressure according to CCT to
Division of Ophthalmology, Faculty of Medicine and Health Sciences, Stellenbosch University, Cape Town, South Africa

Correspondence: SO Baboolal, Division of Ophthalmology, Faculty of Medicine and Health Sciences, Stellenbosch University, Francie Van Zijl Drive, Cape Town, Western Cape 7505, South Africa Tel: +27 729 911995; Fax: +27 219385511 E-mail: sandikababoolal@ gmail.com

Received: 17 April 2017 Accepted in revised form: 26 September 2017 Published online: 12 January 2018 
obtain the corrected intraocular pressure (cIOP). ${ }^{5} \mathrm{CCT}$ therefore has a profound effect on true IOP and the risk of developing glaucoma. Knowledge of the distribution of IOP and CCT in different ethnic populations is critical and useful in both clinical and research settings. Studies of ethnic variation in IOP and CCT show that African Americans have lower CCT measurements and lower IOP than Caucasians. ${ }^{34-39}$ This lower IOP could be an underestimation of the actual IOP as a result of lower CCT readings potentially resulting in an under-diagnosis of ocular hypertension and glaucoma and an increase in the related morbidity. In the Los Angeles Latino Eye Study, the prevalence of glaucoma was higher among individuals with lower CCTs than in individuals with normal or higher CCTs across all levels of intraocular pressure. ${ }^{40}$ South Africa has a diverse population including a group of people with mixed ancestry in whom the relationship between CCT and IOP has not previously been studied. Accurate glaucoma risk stratification is compromised in this important group due to the lack of published normative data.

Overall the prevalence of glaucoma in South Africa is $4.5 \% .{ }^{41}$ The prevalence of glaucoma is between 4.5 and $5.3 \%$ in black South Africans. ${ }^{42,43}$ In comparison, the prevalence of glaucoma in Mixed ethnicity is $4.8 \% .{ }^{44} \mathrm{In}$ the literature, there is only a historical epidemiology study in South Africa from 1973 which reported that the prevalence of glaucoma in Caucasians was $0.002 \% .{ }^{45}$ This would appear to be outdated as our scientific methodology and population profile have evolved but it does highlight the need for further epidemiological glaucoma studies to include all the major ethnic groups of South Africa.

\section{Objectives}

This study aimed to examine the ethnic variations in the distributions of CCT and IOP among the three major South African Ethnic groups: Africans, Mixed ethnicity, and Caucasians. Additionally, we aimed to assess other systemic and ocular factors, which affected CCT and IOP.

\section{Subjects and methods}

\section{Design}

Cross-sectional study in which a one-way analysis of variance (ANOVA) study done pre-recruitment described sample sizes of 105 Africans, 70 Mixed ethnicity, and 35 Caucasians with a total of 210 subjects achieving a power of $80 \%$. In South Africa, it is considered unethical to recruit much more than the sample size deemed to have an adequately powered study.

\section{Setting}

The study was conducted prospectively on volunteers at Tygerberg Academic Hospital from March to September 2016 after informed consent was obtained. It is a tertiary hospital that is the second largest in South Africa and covers a drainage area serving millions of people. In addition, participants recruited from Stellenbosch University and the staff of Tygerberg Hospital includes people from across South Africa. Both the Biostatistics Department and study supervisor (DPS) agreed that the methodology and context was adequate to conduct this epidemiological study.

\section{Participants}

Volunteer convenience sampling was used. Participants underwent interviewer-administered questionnaires to collect demographic data and assess risk factors including family history of glaucoma, medical conditions such as diabetes mellitus, current and previous medication use including steroid use and ocular history including known myopia. Ethnicity was self-reported. Exclusion criteria included: history of glaucoma or previous ocular trauma; corneal edema, scarring, ectasia, or dystrophy; intraocular surgery during the preceding 3 months or any previous refractive surgery; contact lens use; a history/clinical evidence of uveitis and suspicious glaucomatous discs. Each participant underwent a complete slit lamp examination and prior to pupil dilation, the averages of six intraocular pressure readings measured with an Icare PRO tonometer (Icare, Vantaa, Finland) were calculated and CCT was measured with an OCULUS Pentacam (OCULUS Wetzlar, Germany). The Pentacam measurement was repeated until the software determined the quality of the images to be acceptable. The study was approved by the Health Research Ethics Committee of Stellenbosch University and the conduct of the study adhered to the Declaration of Helsinki.

\section{Statistical analysis}

For the person-level analysis, one-way analysis of variance (ANOVA) was performed to compare continuous variables among ethnic groups, and $\chi^{2}$-tests were used for categorical variables.

For the eye-level analysis, to account for some participants having both eyes analysed and some only one eye, analytical weighting was used to adjust for the within-person clustering. Analytical weights are inversely proportional to the variance of an observation. This method was used for one-way ANOVA testing and Bonferroni post hoc tests. Simple and multiple linear regression analysis were used to estimate crude and 
adjusted coefficients for the various outcomes. Clustering by patient identity was dealt with using cluster robust standard errors. Statistical significance was set at a $P$-value of $<0.05$. The data were analysed with Stata Version 14.1 (College Station, TX, USA).

\section{Results}

A total of 402 participants with 706 eyes (158 Africans, 177 Mixed ethnicity, and 67 Caucasians) aged 18-94 years were included in the analysis. About 63 participants were excluded due to the presence of exclusion criteria (61) or participant refusal (2).

The mean age \pm SD was $35 \pm 12$ years for Africans, $48 \pm 17$ years for the Mixed ethnicity, and $47 \pm 20$ years for Caucasians $(P<0.001)$. The average age of all participants was $43 \pm 17$ years. About $61 \%$ of the participants were female. The presence of hypertension was also significantly different between the ethnic groups $(P<0.001)$, but the presence of diabetes was not (Table 1a).

Table $1 \mathrm{~b}$ shows unadjusted associations between ethnic groups and several ocular characteristics using one-way ANOVA testing. The mean IOP levels were clinically similar in all three ethnic groups $(P=0.07)$. When the IOP was corrected for CCT in each ethnic group using the Dresden formula, the corrected mean IOP in the African, Mixed ethnicity, and Caucasian participants were $16.90 \pm 2.45,15.80 \pm 2.25$, and $15.1 \pm 2.35 \mathrm{~mm} \mathrm{Hg}$, respectively $(P<0.001)$. The mean $\mathrm{CCT}$ readings in the Africans (514.77 \pm 31.86$)$, Mixed ethnicity (531.77 \pm 35.17$)$, and Caucasian participants $(549.97 \pm 30.51 \mu \mathrm{m})$ showed significant differences overall and between each ethnicity ( $P<0.001$ for all comparisons).

The CCT mean values and 95\% confidence intervals are contrasted by ethnic group in Figure 1. The presence of myopia was significantly different between the ethnic groups $(P=0.015)$, but the presence of pseudophakia was not different between the Mixed ethnicity and Caucasians $(P=0.864)$.

Table 2 shows the systemic and ocular factors associated with IOP on simple and multiple linear regressions. The difference in mean IOP between each ethnic group was statistically significant when both ocular and systemic factors were adjusted for in the multivariate analysis. It showed Mixed ethnicity $(P=0.034)$, and Caucasians $(P=0.011)$ had a lower intraocular pressure compared to Africans ( 0.54 and $0.88 \mathrm{~mm} \mathrm{Hg}$, respectively).

In the multivariate analysis, age was a systemic factor associated with lower intraocular pressure $(P<0.001)$. Hypertension was associated with a higher intraocular pressure $(P=0.03)$. The ocular factor associated with a higher intraocular pressure was an increased CCT $(P<0.001)$. Pseudophakia was associated with a lower intraocular pressure $(P<0.001)$.

Table 3 shows that self-reported ethnicity was independently associated with thicker corneas $(P<0.001)$. Compared to the Africans, the Caucasians had on average about 34 microns thicker corneas and the Mixed ethnicity had on average 18 microns thicker corneas. Ocular factors associated with an increased central CCT were IOP and pseudophakia (both $P<0.001$ ).

\section{Discussion}

To our knowledge, the South African Eye Study (SAES) is the largest adult epidemiological study in Sub-Saharan Africa (SSA) assessing the ethnic differences in IOP and CCT. In this prospective cross-sectional study of three major adult ethnic groups in South Africa, Africans had

Table 1a Demographic and systemic characteristics among the three ethnic groups

\begin{tabular}{|c|c|c|c|c|c|}
\hline Characteristics & Total $\mathrm{n}=402$ & African $\mathrm{n}=158$ & Mixed ethnicity $\mathrm{n}=177$ & Caucasians $\mathrm{n}=67$ & P-value \\
\hline Age (years) & 43 & 35 & 48 & 47 & $<0.001$ \\
\hline Female & $246(61.2 \%)$ & $97(61.4 \%)$ & $115(65 \%)$ & $33(50.7 \%)$ & $<0.001$ \\
\hline Diabetes & $79(19.7 \%)$ & $23(14.6 \%)$ & $47(26.6 \%)$ & $9(13.4 \%)$ & 0.08 \\
\hline Hypertension & $119(29.6 \%)$ & $22(13.9 \%)$ & $73(41.2 \%)$ & $24(35.8 \%)$ & $<0.001$ \\
\hline
\end{tabular}

Table $1 \mathrm{~b}$ Ocular characteristics among the three ethnic groups

\begin{tabular}{|c|c|c|c|c|c|}
\hline & Total $\mathrm{n}=706$ & African $\mathrm{n}=277$ & Mixed ethnicity $\mathrm{n}=311$ & Caucasians $\mathrm{n}=118$ & P-value \\
\hline IOP (mm Hg) & 15.26 & 15.51 & 15.09 & 15.13 & 0.079 \\
\hline cIOP (mm Hg) & 16.12 & 16.90 & 15.80 & 15.14 & $<0.001$ \\
\hline ССТ $(\mu \mathrm{m})$ & 528.14 & 514.77 & 531.77 & 549.97 & $<0.001$ \\
\hline Myopia $(n(\%))$ & $37(9.2 \%)$ & $9(5.7 \%)$ & $16(9 \%)$ & $12(17.9 \%)$ & 0.015 \\
\hline Pseudophakia $(n(\%))$ & 22 & $0(0 \%)$ & $16(5 \%)$ & $6(5 \%)$ & 0.864 \\
\hline
\end{tabular}


the thinnest corneas followed by Mixed ethnicity.

Caucasians had the thickest corneas similar to the average CCT reported in the literature. ${ }^{34,35}$ The difference in mean IOP between each ethnic group was statistically significant when both ocular and systemic factors were adjusted for in the multivariate analysis. Africans had the highest mean IOP followed by Caucasians and Mixed ethnicity.

Numerous epidemiological studies have been conducted across several Sub-Saharan countries on the normative values of CCT and intraocular pressure in nonglaucomatous participants. A review of the literature collected 1637 non-glaucomatous African patients drawn from five SSA countries (South Africa, Nigeria, Ghana, Cameroon, and Ethiopia). The patients' ages ranged from 5 to 90 years. The outcome of the CCT range was

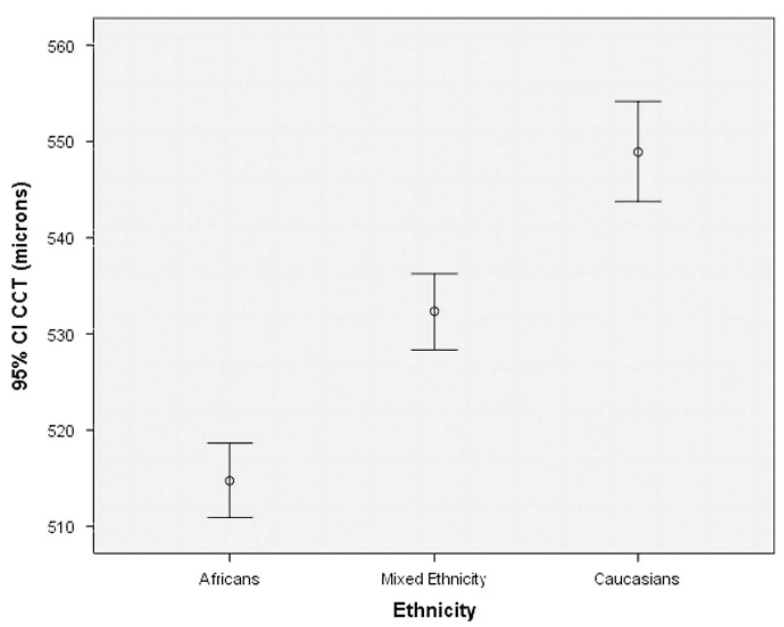

Figure 1 Confidence interval distribution in the different ethnic groups.
$440-670 \mu \mathrm{m}$ and its mean value varied from 512 to $550 \mu \mathrm{m}$ for non-glaucomatous subjects. The thicker and thinner mean values were found in Nigeria and South Africa, respectively. ${ }^{46}$ There has only been one previously published CCT IOP study conducted in South Africa on black Africans: 100 participants aged 18-25 had a CCT of $512.4 \pm 38.9 \mu \mathrm{m}$ with an intraocular pressure between 9$21 \mathrm{~mm} \mathrm{Hg}$ and a mean of $13.8 \mathrm{~mm} \mathrm{Hg} .{ }^{47}$ The CCT mean and SD in Africans in our study was $514.77 \pm 31.86$ and included a larger number of black African participants $(n=158)$ and a wider age distribution (18-79 years). The IOP mean of $15.51 \pm 2.49 \mathrm{~mm} \mathrm{Hg}$ in black Africans in our study was higher than the previous South African based study and showed a positive and consistent correlation between CCT and IOP. Interestingly, 21 Africans from 9 other Sub-Saharan African countries were included (Zimbabwe, Congo, Kenya, Somalia, Burundi, Nigeria, Mozambique, Cameroon, and Malawi). Their mean IOP of $16.41 \mathrm{~mm} \mathrm{Hg}$ was higher than the South Africans' IOP of $15.35 \mathrm{~mm} \mathrm{Hg}(P=0.01)$. The Sub-Saharan black African group also had thicker corneas of $525 \mu \mathrm{m}$ compared to $513 \mu \mathrm{m}$ in South Africans $(P=0.01)$. There are no published normative IOP and CCT values for Africans from Zimbabwe, Congo, Kenya, Burundi, Mozambique, and Malawi. In a small study of Somalian adults, the mean intraocular pressure of Somalians was $13.76 \pm 3.63 \mathrm{~mm} \mathrm{Hg} .{ }^{48}$ In Nigeria, the mean CCT was $548.97 \pm 34.28 \mu \mathrm{m}$ and the mean IOP was $15.61 \pm 2.69 \mathrm{~mm}$ Hg. ${ }^{49}$ In Cameroon, the average CCT was $529.29 \pm 35.9 \mu \mathrm{m}$ and the average IOP was $13.01 \pm 2.97 \mathrm{~mm} \mathrm{Hg} .{ }^{50}$

Africans are more genetically diverse than other populations. Genetic studies suggest that the Mixed ethnicity group in South Africa has the highest levels of

Table 2 Associations of intraocular pressure with systemic and ocular factors

\begin{tabular}{|c|c|c|c|c|c|c|}
\hline \multirow[t]{2}{*}{ Systemic } & \multicolumn{3}{|c|}{ Univariate model } & \multicolumn{3}{|c|}{ Multivariate model ${ }^{\mathrm{a}}$} \\
\hline & $\beta$ & $95 \% C I$ & P-value & $\beta$ & $95 \% C I$ & P-value \\
\hline \multicolumn{7}{|l|}{ Ethnicity } \\
\hline Mixed ethnicity vs Africans & -0.39 & -0.871 to 0.091 & 0.112 & -0.54 & -1.05 to -0.04 & 0.034 \\
\hline Caucasians vs Africans & -0.39 & -1.08 to 0.29 & 0.258 & -0.88 & -1.56 to 0.21 & 0.011 \\
\hline Age & -0.15 & -0.281 to 0.003 & 0.013 & -0.03 & -0.05 to -0.01 & $<0.001$ \\
\hline Gender & 0.274 & -0.191 to 0.170 & 0.248 & 0.303 & -0.13 to 0.74 & 0.170 \\
\hline Diabetes & 0.589 & 0.415 to 1.136 & 0.035 & 0.535 & 0.08 to -0.73 & 0.08 \\
\hline Hypertension & 0.202 & -0.294 to 0.702 & 0.81 & 0.688 & 0.04 to 1.32 & 0.03 \\
\hline \multicolumn{7}{|l|}{ Ocular } \\
\hline CCT & 0.17 & 0.10 to 0.23 & $<0.001$ & 0.02 & 0.01 to 0.02 & $<0.001$ \\
\hline Myopia & -0.26 & 0.51 & -1.04 to 0.52 & -0.16 & -0.92 to 0.50 & 0.67 \\
\hline Pseudophakia & -1.18 & -2.24 to -0.13 & 0.03 & -1.40 & -2.31 to -0.50 & $<0.001$ \\
\hline Constant & & & & 5.35 & 1.99 to 8.70 & 0.002 \\
\hline
\end{tabular}

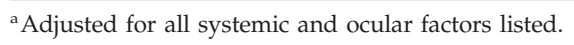


Table 3 Associations of central corneal thickness with systemic and ocular factors

\begin{tabular}{|c|c|c|c|c|c|c|}
\hline \multirow[t]{2}{*}{ Systemic } & \multicolumn{3}{|c|}{ Univariate model } & \multicolumn{3}{|c|}{ Multivariate model } \\
\hline & $\beta$ & $95 \% C I$ & P-value & $\beta$ & $95 \% C I$ & P-value \\
\hline \multicolumn{7}{|l|}{ Ethnicity } \\
\hline Mixed ethnicity vs Africans & 17.519 & 10.01 to 25.02 & $<0.001$ & 15.02 & 7.49 to 22.54 & $<0.001$ \\
\hline Caucasians vs Africans & 34.38 & 26.33 to 42.42 & $<0.001$ & 32.22 & 23.46 to 40.98 & $<0.001$ \\
\hline Age & 0.404 & 0.196 to 0.612 & $<0.001$ & 0.18 & -0.06 to 0.43 & 0.15 \\
\hline Gender & 3.465 & -3.75 to 10.68 & 0.346 & 0.95 & -6.46 to 13.07 & 0.95 \\
\hline Diabetes & 10.09 & 0.31 to 19.88 & 0.043 & 3.30 & -6.47 to 13.07 & 0.51 \\
\hline Hypertension & 13.31 & 5.546 to 21.07 & 0.001 & -0.01 & -9.42 to 9.39 & 0.99 \\
\hline \multicolumn{7}{|l|}{ Ocular } \\
\hline IOP & 3.78 & 2.42 to 5.13 & $<0.001$ & 4.39 & 3.24 to 5.53 & $<0.001$ \\
\hline Myopia & 4.63 & -9.61 to 18.89 & 0.52 & 1.80 & -12.08 to 15.68 & 0.80 \\
\hline Pseudophakia & 30.32 & 13.83 to 46.82 & $<0.001$ & 22.88 & 8.63 to 37.14 & 0.002 \\
\hline Constant & & & & 439.63 & 419.02 to 460.24 & $<0.001$ \\
\hline
\end{tabular}

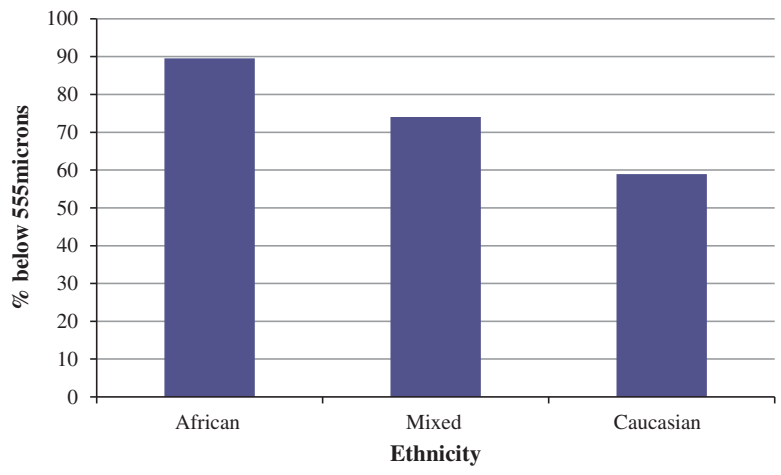

Figure 2 Percentage of each ethnic group with CCT $<555$ microns.

mixed ancestry in the world. ${ }^{51-53}$ Our study showed that Mixed ethnicity participants had a mean CCT of $531.77 \pm 35.17$ microns. This is the first study to describe the ocular characteristics of this unique ethnic group.

In several studies including the Barbados Eye Study Group, black participants had thinner corneas ${ }^{54}$ (mean thickness, $529.8 \mu \mathrm{m}$ ) compared to mixed (black and white) $(537.8 \mu \mathrm{m})$ and white participants $(545.2 \mu \mathrm{m})$, respectively. ${ }^{55}$ In our study, the CCT of South African Caucasian participants was $549.97 \pm 30.5$ microns $(P<0.001)$. It is the first epidemiological study in SubSaharan Africa to report on the normative CCT and IOP values of the Caucasian ethnic group.

In the OHTS, a multivariate model showed that a thinner CCT was an important predictive factor for the development of POAG. The OHTS reports a thin CCT of $<555$ microns as an independent risk factor for glaucoma. ${ }^{56}$ Our study found that the majority of South African participants across ethnic groups have this risk factor. $89.52 \%$ of Africans, $74.01 \%$ of Mixed ethnicity, and
$58.96 \%$ of Caucasians had a thin CCT as per OHTS definition illustrated by Figure 2. But this was a completely different population sample based in the United States and highlights the need to clinically integrate CCT in an ethnic and population-specific manner so that a thin cornea is more specifically defined. This will lead to more accurate glaucoma risk stratification in different population groups.

\section{Associations between IOP and age}

Previous studies have found that IOP increases with age, ${ }^{57,58}$ while other studies have found no correlation with age. ${ }^{59}$ These differences may be population-specific. African populations and their genomes are highly complex. The bio-geographic variations within South Africa, which includes both indigenous and non-African population groups are further aspects to consider. Cape Town is an urban location and this will also impact on the results. In our study, there was ethnic variation in the multivariate analysis. In Africans, IOP increased with age $(P=0.88)$ while in Mixed ethnicity participants IOP decreased with age $(P=0.19)$. In Caucasians, IOP increased with age under 40 years of age $(P=0.33)$ but decreased over 40 years of age $(P=0.01)$.

Above 50, there was a strong negative association between age and IOP. IOP decreases with age adjusted for race by an average of $0.8 \mathrm{~mm} \mathrm{Hg}$ compared to those $<50$ years.

\section{Diurnal variations with central corneal thickness and intraocular pressure}

Our study found no statistically significant fluctuations in IOP and CCT measurements at different times of the day 
(0700 or 1800 hours). There was a trend for CCT to be higher in the afternoon $(P=0.5)$ in contrast to previous smaller studies where CCT was found to be thickest in the morning and gradually thinned as the day progressed. ${ }^{60-63}$ There was also a trend for IOP to be lower $(P=0.63)$ in the afternoon, which is similar to the results of previous studies. ${ }^{64}$ But overall, none of these trends were statistically significant; thus, the time of day that the measurements were taken was not a confounding factor.

\section{Ocular factor associations with central corneal thickness and IOP}

In the multivariate analysis, IOP was $1.40 \mathrm{~mm} \mathrm{Hg}$ less in pseudophakic eyes $(P<0.001)$. This correlates with previous studies that report a drop in IOP of about $1.5 \mathrm{~mm} \mathrm{Hg}$ in non-glaucomatous patients. ${ }^{65}$

Ocular factors associated with an increased CCT were IOP and pseudophakia $(P<0.001)$. For every 4 microns increase in thickness, IOP increased by $1 \mathrm{~mm} \mathrm{Hg}$ overall.

In addition, corneal hysteresis $(\mathrm{CH})$ may also be related to optic nerve/laminar biomechanics. It has been shown that combining $\mathrm{CH}$ and $\mathrm{CCT}$ for glaucoma risk assessment improves diagnostic capability compared to using either factor alone. ${ }^{66}$

\section{Study strengths and limitations}

In this study, ethnicity was self-reported, which is in keeping with most studies examining ethnic differences of IOP and CCT but this is prone to information bias. ${ }^{35,37-40,46,47,52-54}$ Genetic African ancestry (GAA) may be a less 'prejudiced' method to analyze the data. But GAA introduces its own biases to the process since broad coverage of African populations with ethnic diversity are not currently represented.

The strengths of the study include a moderately sized multi-ethnic sample group. Standardized study methodology was used to prospectively collect data for each ethnic group. The average of six IOP readings was taken, which is more accurate than a single measurement. CCT was measured using the Pentacam, which is an accurate means of obtaining this data and measurements were repeated until an acceptable quality was achieved and thus accuracy was ensured. Data were collected from a Mixed ethnicity group not previously reported in the literature. Certain sub-group analysis revealed correlations not previously described in the literature and confirmed trends reported in other studies. This study could serve as a starting point for future genetics-based studies, which could aim to identify the gene(s) responsible for the differences described.

\section{Conclusion and relevance}

This study confirms the ethnic variations of CCT and reports on a Mixed ethnicity group with rich genetic ancestry not previously studied. Africans have the thinnest corneas among the three ethnic groups followed by Mixed ethnicity and Caucasians. The majority of all ethnic groups have a CCT of $<555$ microns, which emphasizes the need for ethnic and population-specific definitions of a thin cornea. Both measured and cIOP adjusted for CCT was highest in Africans. Hypertension correlated with an increased intraocular pressure. Age was associated with a decrease in intraocular pressure. Increased CCT was strongly associated with an increased intraocular pressure. Pseudophakia was associated with an increased CCT and a decreased intraocular pressure. Systemic and ocular factors influence IOP and CCT. There is a need for refining risk factor definitions, which are population and ethnic specific. Including these refined influences will lead to more accurate clinical risk stratification and prognostication for glaucoma screening and management. This has important public health and clinical-care implications.

\section{Summary}

What was known before

- Ethnic differences occur between central corneal thickness and intraocular pressure of different populations and ethnicities, and this influences intraocular pressure readings which impact on glaucoma screening.

What this study adds

- Establishes normative data of central corneal thickness and intraocular pressure in the South African population's majority ethnic groups.

- Compares the normative data of the South African Eye Study to other international studies with implications for glaucoma screening and prognostication.

- The first epidemiological study of this type that addresses the role of African ancestry in endophenotypes CCT and IOP.

\section{Conflict of interest}

The authors declare no conflict of interest.

\section{Acknowledgements}

We thank Tonya M Esterhuizen, Biostatistician, Stellenbosch University, Cape Town, South Africa. The study was supported by the Discovery Foundation Academic Fellowship Award, Discovery Foundation, Parktown, Johannesburg. 


\section{Disclaimer}

The funding organization had no role in the design or conduct of this research.

\section{References}

1 Cook C, Foster P. Epidemiology of glaucoma: what's new. Can J Ophthalmol 2012; 47(3): 223-226.

2 Kyari F, Abdull MM, Bastawrous A, Gilbert CE, Faal H. Epidemiology of glaucoma in Sub-Saharan Africa: prevalence, incidence and risk factors. Middle East Afr J Ophthalmol 2013; 20: 111-125.

3 Quigley HA, Broman AT. The number of people with glaucoma worldwide in 2010 and 2020. Br J Ophthalmol 2006; 90: 262-267.

4 Dielemans I, Vingerling JR, Wolfs RC, Hofman A, Grobbee $\mathrm{DE}$, de Jong PT. The prevalence of primary open-angle glaucoma in a population-based study in the Netherlands. The Rotterdam study. Ophthalmology 1994; 101: 1851-1855.

5 Martin MJ, Sommer A, Gold EB, Diamond EL. Race and primary open-angle glaucoma. Am J Ophthalmol 1985; 99: 383-387.

6 Ostermann J, Sloan FA, Herndon L, Lee PP. Racial differences in glaucoma care: the longitudinal pattern of care. Arch Ophthalmol 2005; 123: 1693-1698.

7 Grant WM, Burke JF Jr. Why do some people go blind from glaucoma? Ophthalmology 1982; 89: 991-998.

8 Wilson R, Richardson TM, Hertzmark E, Grant WM. Race as a risk factor for progressive glaucomatous damage. Ann Ophthalmol 1985; 17: 653-659.

9 Ntim-Amponsah CT, Winifried MK, Ofosu-Amah S. Awareness and knowledge of glaucoma and other diseases associated with blindness in a Ghanian community. Niger J Ophthalmol 2004; 12: 50-54.

10 Balo PK, Serouis G, Banla M, Agla K, Djagnikpo PA, Gué $\mathrm{KB}$. Knowledge, attitudes and practices regarding glaucoma in the urban and suburban population of Lomé (Togo). Sante 2004; 14: 187-191.

11 Bodunde OT, Daneil OJ, Onobolu OO, Ajibode HA, Awodein OG, Jagun OO et al. Knowledge, attitude and health beliefs of glaucoma patients in a Nigerian hospital. Niger Med Pract 2006; 50: 62-64.

12 Mwanza JC. Primary open-angle glaucoma in Sub-Saharan Africa. Niger J Ophthalmol 2006; 14: 22-26.

13 Adegbehingbe BO, Bisiriyu LA. Knowledge, attitudes, and self care practices associated with glaucoma among hospital workers in Ile-Ife, Osun State, Nigeria. Tanzan J Health Res 2008; 10: 240-245.

14 Onyekwe LO, Okosa MC, Apakama AI. Knowledge and attitude of eye hospital patients towards chronic open angle glaucoma in Onitsha. Niger Med J 2009; 50: 1-3.

15 Tenkir A, Solomon B, Deribew A. Glaucoma awareness among people attending ophthalmic outreach services in Southwestern Ethiopia. BMC Ophthalmol 2010; 10: 17.

16 Nwosu SN. Patients' knowledge of glaucoma and treatment options. Niger J Clin Pract 2010; 13: 74-77.

17 Cook C. Glaucoma in Africa: size of the problem and possible solutions. J Glaucoma 2009; 18: 124-128.

18 Egbert PR. Glaucoma in West Africa: a neglected problem. Br J Ophthalmol 2002; 86: 131-132.

19 Chuka-Okosa CM, Faal HB. Glaucoma services in the Gambia. Niger J Ophthalmol 2003; 11: 19-23.
20 Omoti AE. A review of the choice of therapy in primary open angle glaucoma. Niger J Clin Pract 2005; 8: 29-34.

21 Rotchford A. What is practical in glaucoma management? Eye 2005; 19: 1125-1132.

22 Olatunji FO, Ibrahim UF, Muhammad N, Msheliza AA, Ibrahim UY, Rano BT et al. Challenges of glaucoma service delivery in Federal Medical Centre, Azare, Nigeria. Afr J Med Med Sci 2008; 37: 355-359.

23 Standefer JE. Challenges in glaucoma management in developing countries: is vision 2020 ready for glaucoma? Niger J Ophthalmol 2009; 18: 1-2.

24 Patel D, Mercer E, Mason I. Ophthalmic equipment survey 2010: preliminary results. Community Eye Health 2010; 23: 22-25.

25 Ashaye AO. Clinical features of primary glaucoma in Ibadan. Niger J Ophthalmol 2003; 11: 70-75.

26 Lawan A. Pattern of presentation and outcome of surgical management of primary open angle glaucoma in Kano, Northern Nigeria. Ann Afr Med 2007; 6: 180-185.

27 Gyasi M, Amoako W, Adjuik M. Presentation patterns of primary open angle glaucomas in North Eastern Ghana. Ghana Med J 2010; 44: 25-30.

28 Chukwuka IO, Ejimadu CS, Pedro-Egbe CN. Clinical features of primary glaucoma in South East Nigeria. Ann Biomed Sci 2012; 11: 88-95.

29 Omoti AE, Osahon AI, Waziri-Erameh MJ. Pattern of presentation of primary open-angle glaucoma in Benin City, Nigeria. Trop Doct 2006; 36: 97-100.

30 Olatunji FO, Ibrahim UF, Muhammad N, Msheliza AA, Akku BB, Ibrahim UY et al. The types and treatment of glaucoma among adults in North Eastern part of Nigeria. Tanzan Med J 2009; 24: 24-28.

31 Faal H. Primary open-angle glaucoma: everyone's business. Community Eye Health 2012; 25: 41-43.

32 Doughty M, Zaman M.. Human corneal thickness and its impact on intraocular pressure measures: a review and metaanalysis approach. Surv Ophthalmol 2000; 44 (5):367-408.

33 Wolfs RC, Klaver CC, Vingerling JR, Grobbee DE, Hofman A, de Jong PT. Distribution of central corneal thickness and its association with intraocular pressure: the Rotterdam Study. Am J Ophthalmol 1997; 123(6): 767-772.

34 Shimmyo M, Ross AJ, Moy A, Mostafavi R. Intraocular pressure, Goldmann applanation tension, corneal thickness and corneal curvature in Caucasians, Asians, Hispanics and African Americans. Am J Ophthalmol 2003; 136(4): 603-613.

35 La Rosa F, Gross RL, Orengo-Nania S. Central corneal thickness of Caucasians and African Americans in glaucomatous and non-glaucomatous populations. Arch Ophthalmol 2001; 119(1): 23-27.

36 Chua J, Tham YC, Liao J, Zheng Y, Aung T, Wong TY et al. Ethnic differences of intraocular pressure and central corneal thickness: the Singapore Epidemiology of Eye Diseases Study. Am Acad Ophthalmol 2014; 121(10): 2013-2022.

37 Tielsch JM, Sommer A, Katz J, Royall RM, Quigley HA, Javitt $J$. Racial variations in the prevalence of primary open angle glaucoma: the Baltimore Eye Survey. JAMA 1991; 266(3): 369-374.

38 Herndon L, Weizer S. Central corneal thickness as a risk factor for advanced glaucoma damage. JAMA 2004; 122(1): $17-22$.

39 Gordon MO, Beiser JA, Brandt JD, Heuer DK, Higginbotham EJ, Johnson CA et al. The Ocular Hypertension Treatment Study: baseline factors that predict the onset of primary open-angle glaucoma. Arch Ophthalmol 2002; 120(6): 714-720. 
40 Varma R, Paz SH, Azen SP, Klein R, Globe D, Torres M et al. The Los Angeles Latino Eye Study: design methods and baseline data. Ophthalmology 2004; 111(6): 1121-1131.

41 Kyari F, Abdull MM, Bastawrous A, Gilbert CE, Faal H. "Epidemiology of glaucoma in sub-Saharan Africa: prevalence, incidence and risk factors". Middle East Afr J Ophthalmol 2013; 20: 111-125.

42 Rotchford AP, Johnson. GJ. "Glaucoma in Zulus: a population-based cross-sectional survey in a rural district in South Africa". Arch Ophthalmol 2002; 120: 471-478.

43 Rotchford AP, Kirwan JF, Muller MA, Johnson GJ, Roux P et al. "Temba glaucoma study: a population-based crosssectional survey in urban South Africa". Ophthalmology 2003; 110: 376-382.

44 Salmon JF, Mermoud A, Ivey A, Swanevelder SA, Hoffman $M$. "The prevalence of primary angle closure glaucoma and open angle glaucoma in Mamre, western Cape, South Africa". Arch Ophthalmol 1993; 111: 1263-1269.

45 Luntz Maurice H. "Primary angle-closure glaucoma in urbanized South African caucasoid and negroid communities". Br J Ophthalmol 1973; 57: 445-456.

46 Joella SE, Ndjiembi CA, Marce-Amara K, Rajaonarison HO, Huyi Z. Central corneal thickness measurement in SubSaharan Africa: review. IOSR J Humanities Soc Sci 19(2): 111-120.

47 Sardiwalla Z, Moodley D, Ndawonde T, Madikizela A, Ngobese N, Thobela N. A comparative study of central corneal thickness (CCT) and intraocular pressure (IOP) in University of KwaZulu-Natal students of Black and Indian ethnicity. Afr Vis Eye Health 2012; 71 (4):171-177.

48 Read RW, Chen PP, Bhandari A, Mills RP, Cinciripini GS, Taylor CC. Intraocular pressure in a Somali population living in the United States. J Glaucoma 2003; 12(4)) : 365-369.

49 Iyamu E, Osuobeni E. "Age, gender, corneal diameter, corneal curvature and central corneal thickness in Nigerians with normal intra ocular pressure". J Optom 2012; 5: 87-97.

50 Eballe AO, Koki G, Ellong A, Owono D, Epée E, Bella LA et al. "Central corneal thickness and intraocular pressure in the Cameroonian nonglaucomatous population". Clin Ophthalmol 2010; 4: 717.

51 Petersen DC, Libiger O, Tindall EA, Hardie RA, Hannick LI, Glashoff RH et al. Complex patterns of genomic admixture within Southern Africa. PLoS Genet 2013; 9(3): e1003309.

52 Campbell MC, Tishkoff SA. African Genetic Diversity: Implications for Human Demographic History, Modern Human Origins, and Complex Disease Mapping. Annu Rev Genomics Hum Genet 2008; 9: 403-433.
53 Tishkoff SA, Reed FA, Friedlaender FR, Ehret C, Ranciaro A, Froment A et al. The genetic structure and history of Africans and African Americans. Science 2009; 324(5930): 1035-1044.

54 La Rosa FA, Gross RL, Orengo-Nania S. Central corneal thickness of Caucasians and African Americans in glaucomatous and non-glaucomatous populations. Arch Ophthalmol 2001; 119(1): 23-27.

55 Nemesure B, Wu SY, Hennis A, Leske MC, Barbados Eye Study Group. Corneal thickness and intraocular pressure in the Barbados eye studies. Arch Ophthalmol 2003; 121(2): 240-244.

56 Brandt JD, Beiser JA, Kass MA, Gordon MO. Ocular Hypertension Treatment Study (OHTS) Group, Central Corneal Thickness in the Ocular Hypertension Treatment Study (OHTS). Ophthalmology 2001; 108: 1779-1788.

57 Qureshi IA. Age and intraocular pressure: how are they correlated? J Pak Med Assoc 1995; 45(6): 150-152.

58 Wong TT, Wong TY, Foster PJ, Crowston JG, Fong CW, Aung T, SiMES Study Group. The relationship of intraocular pressure with age, systolic blood pressure, and central corneal thickness in an Asian population. Invest Ophthalmol Vis Sci 2009; 50(9): 4097-4102.

59 Rochtchina E, Mitchell P, Wang JJ. Relationship between age and intraocular pressure: the Blue Mountains Eye Study . Clin Exp Ophthalmol 2002; 30 (3):173-175.

60 Harper CL, Boulton ME, Bennett D, Marcyniuk B, JarvisEvans JH, Tullo AB et al. Diurnal variations in human corneal thickness. Br J Ophthalmol 1996; 80: 1068-1072.

61 Kiely PM, Carney LG, Smith G. Diurnal variations of corneal topography and thickness. Am J Optom Physiol Opt 1982; 59: 976-982.

62 Toit R, Vega J, Fonn D, Simpson L. Diurnal variation of corneal sensitivity and thickness. Am J Optom 2003; 22: 205-209.

63 Read SA, Collins MJ. Diurnal variation of corneal shape and thickness. Optom Vis Sci 2009; 86: 170-180.

64 Pointer JS. The diurnal variation of intraocular pressure in non-glaucomatous subjects: relevance in a clinical context. Ophthalmic Physiol Opt 1997; 17: 456-465.

65 Shingleton BJ, Pasternack JJ, Hung JW, O'Donoghue MW. Three and five year changes in intraocular pressures after clear corneal phacoemulsification in open angle glaucoma patients, glaucoma suspects, and normal patients. J Glaucoma 2006; 15: 494-498.

66 Pensyl D, Sullivan-Mee M, Torres-Monte M, Halverson K, Qualls C. Combining corneal hysteresis with central corneal thickness and intraocular pressure for glaucoma risk assessment. Eye 2012; 26(10): 1349-1356. 